\title{
Nutrients for the aging eye
}

This article was published in the following Dove Press journal:

Clinical Interventions in Aging

19 June 2013

Number of times this article has been viewed

\section{Helen M Rasmussen' \\ Elizabeth J Johnson ${ }^{2}$}

'Educational Studies, Lesley University, Cambridge, MA, USA; ${ }^{2}$ Carotenoid and Health Laboratory, Jean Mayer US Department of Agriculture Human Nutrition Research Center on Aging at Tufts University, Boston, MA, USA
Correspondence: Elizabeth J Johnson Carotenoid and Health Laboratory, Jean Mayer US Department of Agriculture Human Nutrition Research Center on Aging at Tufts University, 7II Washington Street, Boston, MA 021II, USA

$\mathrm{Tel}+\mathrm{I} 6175563204$

Fax +l 6175563344

Email elizabeth.johnson@tufts.edu
Abstract: The incidence of age-related eye diseases is expected to rise with the aging of the population. Oxidation and inflammation are implicated in the etiology of these diseases. There is evidence that dietary antioxidants and anti-inflammatories may provide benefit in decreasing the risk of age-related eye disease. Nutrients of interest are vitamins $\mathrm{C}$ and $\mathrm{E}$, $\beta$-carotene, zinc, lutein, zeaxanthin, and the omega-3 fatty acids eicosapentaenoic acid and docosahexaenoic acid. While a recent survey finds that among the baby boomers ( $45-65$ years old), vision is the most important of the five senses, well over half of those surveyed were not aware of the important nutrients that play a key role in eye health. This is evident from a national survey that finds that intake of these key nutrients from dietary sources is below the recommendations or guidelines. Therefore, it is important to educate this population and to create an awareness of the nutrients and foods of particular interest in the prevention of age-related eye disease.

Keywords: nutrition, aging, eye health

\section{Introduction}

The number of Americans age 55 years and older will almost double between now and 2030, from 60 million to 108 million (http://www.census.gov/prod/2010pubs/p25-1138. pdf). This age-group suffers an increased incidence of age-related diseases, including such eye diseases as cataract, diabetic retinopathy, glaucoma, and age-related macular degeneration (AMD). Attention has focused on efforts to stop the progression of eye diseases or to prevent the damage leading to these conditions. Nutritional intervention is becoming recognized as a part of these efforts. Compared to most other organs, the eye is particularly susceptible to oxidative damage due to its exposure to light and high metabolism. Recent literature indicates that nutrients important in vision health include vitamins and minerals with antioxidant functions (eg, vitamins $\mathrm{C}$ and $\mathrm{E}$, carotenoids [lutein, zeaxanthin, $\beta$-carotene], zinc), ${ }^{1}$ and compounds with anti-inflammatory properties (omega-3 fatty acids (eicosapentaenoic acid [EPA], docosahexaenoic acid [DHA])) ${ }^{2}$ may ameliorate the risk for age-related eye disease. A recent survey conducted by the Ocular Nutrition Society found that $70 \%$ of the current population (baby boomers) in the age-range 45-65 years ranked vision as the most important of the five senses, yet well over half of those surveyed were not aware of the important nutrients that play a key role in eye health. ${ }^{3}$

The Age-Related Eye Disease Study (AREDS), sponsored by the federal government's National Eye Institute, found that supplementation with vitamins $\mathrm{C}$ and $\mathrm{E}$, 
Table I Nutrient content of the Age-Related Eye Disease Study (AREDS) formulation

\begin{tabular}{lll}
\hline Nutrient & Daily dosage & \% daily value \\
\hline Vitamin C (ascorbic acid) & $452 \mathrm{mg}$ & 754 \\
Vitamin E (DL- $\alpha$-tocopheryl & $400 \mathrm{IU}$ & 1334 \\
acetate) & & \\
Zinc (zinc oxide) & $69.6 \mathrm{mg}$ & 464 \\
Copper (cupric oxide) & $1.6 \mathrm{mg}$ & 80 \\
Vitamin A ( $\beta$-carotene) & $28,640 \mathrm{IU}(17 \mathrm{mg})$ & 572 \\
\hline
\end{tabular}

$\beta$-carotene, zinc, and copper (Table 1) at levels well above the recommended daily allowances reduced the risk of developing advanced AMD by about $25 \% .{ }^{4}$ Copper was added to prevent copper-deficiency anemia, a condition associated with high levels of zinc intake. ${ }^{5}$ Based on these results, the AREDS formulation is considered the standard of care for those at high risk for advanced AMD. The dietary information from AREDS pointed to the carotenoids lutein and zeaxanthin and the omega- 3 fatty acids EPA and DHA as being protective against developing AMD. ${ }^{6,7}$ AREDS2 (www.nei.nih.gov/areds2), a multicenter phase III randomized clinical trial, accessed the effects of oral supplementation of macular xanthophylls, lutein + zeaxanthin, and/or EPA + DHA as a treatment for cataract, AMD, and moderate vision loss. In secondary analysis, lutein and zeaxanthin supplements on top of the AREDS supplement lowered the progression to advanced AMD in persons with low dietary lutein and zeaxanthin. ${ }^{8}$

The purpose of this paper is to describe the nutrients of interest for age-related vision health and to identify rich dietary sources of these nutrients.

\section{Vitamin C}

Vitamin $\mathrm{C}$, also known as ascorbic acid, is an important water-soluble vitamin. Vitamin $\mathrm{C}$ is available in many forms, but there is little scientific evidence that any one form is absorbed better or has more activity than another. Most experimental and clinical research uses ascorbic acid or sodium ascorbate. Natural and synthetic L-ascorbic acid are chemically identical, and there are no known differences in their biological activities or bioavailabilities. ${ }^{9}$

Vitamin $\mathrm{C}$ is required for the synthesis of collagen, an important structural component of blood vessels, tendons, ligaments, and bone. ${ }^{10}$ Vitamin $\mathrm{C}$ is also a highly effective antioxidant, protecting essential molecules in the body, such as proteins, lipids, carbohydrates, DNA, and RNA, from damage by free radicals and reactive oxygen species that can be generated during normal metabolism as well as through exposure to toxins and such pollutants as cigarette smoke. The eye has a particularly high metabolic rate, and thus has an added need for antioxidant protection. Plasma concentrations of vitamin $\mathrm{C}$, an indicator of intake, are related to levels in the eye tissue. ${ }^{11}$ In the eye, vitamin $\mathrm{C}$ may also be able to regenerate other antioxidants, such as vitamin E. ${ }^{12}$

The recommended dietary allowance (RDA) for vitamin $\mathrm{C}$ is $75 \mathrm{mg} /$ day for women ( $\geq 19$ years old) and $90 \mathrm{mg} /$ day for men ( $\geq 19$ years old). ${ }^{10}$ Based on the intake data from the National Health and Nutrition Examination Survey (NHANES), ${ }^{13}$ the average intake of vitamin $\mathrm{C}$ from foods in the US for men and women over 50 years of age is 93 and $88 \mathrm{mg} /$ day, respectively (Table 2). However, men in the 50th percentile or below for vitamin C intake from diet and women in the 25 th percentile or below have intakes that are less than the RDA (Table 2). Vitamin C-rich foods and some suggested serving sizes are shown in Table 3.

\section{Vitamin E}

The term "vitamin E" describes a family of eight fat-soluble antioxidants: four tocopherols $(\alpha-, \beta-, \gamma-$, and $\delta$-) and four tocotrienols $(\alpha-, \beta-, \gamma-$, and $\delta$-). $\alpha$-Tocopherol is the form of vitamin $\mathrm{E}$ that is actively maintained in the human body and also the major form in blood and tissues. ${ }^{14}$ It is also the chemical form that meets the RDA for vitamin E. The main function of $\alpha$-tocopherol in humans appears to be that of an antioxidant. Fats, which are an integral part of all cell membranes, are vulnerable to destruction through oxidation by free radicals. $\alpha$-Tocopherol attacks free radicals to prevent a chain reaction of lipid oxidation. This is important, given that the retina is highly concentrated in fatty acids. ${ }^{2}$ When a molecule of $\alpha$-tocopherol neutralizes a free radical, it is altered in such a way that its antioxidant capacity is lost. However, other antioxidants, such as vitamin C, are capable of regenerating the antioxidant ability of $\alpha$-tocopherol. ${ }^{15}$

Other functions of $\alpha$-tocopherol that would be of benefit to ocular health include effects on the expression and activities of molecules and enzymes in immune and inflammatory cells. Furthermore, $\alpha$-tocopherol has been shown to inhibit platelet aggregation and to improve vasodilation. ${ }^{10,16}$

The RDA for vitamin $\mathrm{E}$ is $15 \mathrm{mg} /$ day $\alpha$-tocopherol for both women and men ( $\geq 19 \mathrm{yrs}) .{ }^{10}$ The average intake of vitamin $\mathrm{E}$ from foods in the US for men and women over 50 years of age is 8.6 and $7.3 \mathrm{mg} /$ day, respectively (Table 2). Only men and women in the 95th percentile of vitamin E intake or greater have intakes of vitamin $\mathrm{E}$ from diet that meet the RDA. Vitamin E-rich foods and some suggested serving sizes are shown in Table 4. 
Table 2 Intake in men $(n=1178)$ and women $(n=1215)$ over 50 years of age $(m g)$ based on NHANES 2009-10

\begin{tabular}{|c|c|c|c|c|c|c|c|c|c|c|c|c|c|}
\hline & \multirow[t]{2}{*}{ Sex } & \multirow[t]{2}{*}{ RDA } & \multirow{2}{*}{$\begin{array}{l}\text { Recommendation } \\
\text { for decreased } \\
\text { disease risk }\end{array}$} & \multirow[t]{2}{*}{ Mean \pm SEM } & \multicolumn{9}{|c|}{ Weighted percentiles } \\
\hline & & & & & $\mathbf{P I}$ & P5 & PIO & $\mathbf{P} 25$ & P50 & P75 & P90 & P95 & P99 \\
\hline \multirow[t]{2}{*}{ Vitamin C, mg/day } & Men & 90 & - & $93.1 \pm 2.2$ & 4.5 & 12.0 & 21.2 & 38.0 & 72.9 & $126 . \mid$ & 196.3 & 247.4 & 322.7 \\
\hline & Women & 75 & - & $88.4 \pm 1.9$ & 5.0 & 13.9 & 21.8 & 39.5 & 75.2 & 122.5 & 168.6 & 200.1 & 293.2 \\
\hline Vitamin E & Men & 15 & - & $8.6 \pm 0.2$ & 1.6 & 3.3 & 3.8 & 5.4 & 7.5 & 10.3 & 14.5 & 17.8 & 30.5 \\
\hline $\begin{array}{l}\text { (as } \alpha \text {-tocopherol), } \\
\mathrm{mg} / \text { day }\end{array}$ & Women & 15 & - & $7.3 \pm 0.1$ & 1.7 & 2.5 & 3.3 & 4.4 & 6.3 & 8.8 & 12.3 & 15.2 & 22.8 \\
\hline \multirow[t]{2}{*}{$\beta$-carotene, mg/day } & Men & - & $3-6 \mathrm{mg}^{*}$ & $2.6 \pm 0.1$ & 0.1 & 0.2 & 0.3 & 0.6 & 1.4 & 3.1 & 6.2 & 9.0 & 14.8 \\
\hline & Women & - & $3-6 m g^{*}$ & $2.7 \pm 0.1$ & 0.1 & 0.2 & 0.3 & 0.7 & 1.7 & 3.8 & 6.3 & 8.9 & 12.9 \\
\hline \multirow[t]{2}{*}{ Zinc, mg/day } & Men & II & - & $13.5 \pm 0.2$ & 4.2 & 5.7 & 6.7 & 8.8 & 12.3 & 16.5 & 22.4 & 25.8 & 37.5 \\
\hline & Women & 8 & - & $9.8 \pm 0.1$ & 2.9 & 4.3 & 5.1 & 6.9 & 8.8 & 11.6 & 15.4 & 18.6 & 25.1 \\
\hline \multirow{2}{*}{$\begin{array}{l}\text { Lutein/zeaxanthin, } \\
\mathrm{mg} / \text { day }\end{array}$} & Men & - & $6 \mathrm{mg} * *$ & $1.2 \pm 0.1$ & 0.1 & 0.2 & 0.3 & 0.6 & 1.0 & 1.8 & 2.9 & 4.9 & 13.5 \\
\hline & Women & - & $6 \mathrm{mg} * *$ & $1.8 \pm 0.1$ & 0.1 & 0.2 & 0.3 & 0.6 & 1.0 & 2.1 & 4.0 & 6.6 & 11.8 \\
\hline \multirow[t]{2}{*}{$\mathrm{EPA}+\mathrm{DHA}, \mathrm{mg} / \mathrm{day}$} & Men & - & $250-1000 * * *$ & $120.6 \pm 6.1$ & 1.5 & 5.0 & 9.0 & 19.5 & 47.5 & 126.5 & 278.0 & 471.5 & 1027.5 \\
\hline & Women & - & $250-1000 * * *$ & $13.5 \pm 0.2$ & 4.2 & 5.7 & 6.7 & 8.8 & 12.3 & 16.5 & 22.4 & 25.8 & 37.5 \\
\hline
\end{tabular}

Notes: Values in bold indicate values less than RDA or recommendation based on current knowledge of relationships between intakes and risk of disease. *Recommendation based on Panel on Dietary Antioxidants and Related Compounds, Subcommittee on Upper Reference Levels of Nutrients, Subcommittee on Interpretation and Uses of DRIs, Standing Committee on the Scientific Evaluation of Dietary Reference Intakes; ${ }^{* * *}$ recommendation based on Seddon et al; ${ }^{26}$ ***recommendation based on Kris-Etherton et al. ${ }^{33}$ Abbreviations: NHANES, National Health and Nutrition Examination Survey; RDA, recommended dietary allowance; SEM, standard error of mean; EPA, eicosapentaenoic acid; DHA, docosahexaenoic acid; DRI, dietary reference intake.

\section{$\beta$-carotene}

$\beta$-Carotene is an orange pigment commonly found in fruits and vegetables and belongs to a class of compounds called carotenoids. Among the carotenoids, $\beta$-carotene is the primary dietary source of provitamin A. ${ }^{17}$ The best evidence that $\beta$-carotene may play a role in age-related eye disease comes from the AREDS1 trial, in which supplementation

Table 3 Vitamin C content of foods $s^{43, *}$

\begin{tabular}{|c|c|c|}
\hline Food & Serving & Milligrams \\
\hline Blackberries & $\mathrm{I} / 2$ cup (72 g) & 15 \\
\hline Blueberries & $\mathrm{I} / 2$ cup $(74 \mathrm{~g})$ & 7 \\
\hline Broccoli, raw & I/2 cup (44 g) & 39 \\
\hline Brussels sprouts, cooked & I/2 cup (78 g) & 48 \\
\hline Cabbage, raw, chopped & I/2 cup (45 g) & 16 \\
\hline Cantaloupe & $\mathrm{I} / 2$ medium (69 g) & 25 \\
\hline Cauliflower, cooked & $\mathrm{I} / 2$ cup (62 g) & 28 \\
\hline Grapefruit, raw, pink & I/2 medium (128g) & 44 \\
\hline Grapefruit juice & I cup (247 g) & 94 \\
\hline Green peppers, raw & I/2 cup (46 g) & 37 \\
\hline Orange & I medium $(14 \mathrm{~g})$ & 63 \\
\hline Orange juice & I cup (248 g) & 124 \\
\hline Papaya & I small (I57 g) & 96 \\
\hline Potato, boiled with peel & 2 I/2" diameter (136 g) & 18 \\
\hline Spinach, raw, chopped & I cup (38 g) & 11 \\
\hline Strawberries, raw, sliced & $\mathrm{I} / 2 \operatorname{cup}(83 \mathrm{~g})$ & 49 \\
\hline Tomato, raw & I medium (123 g) & 17 \\
\hline Tomato juice & I cup $(240 \mathrm{~g})$ & 22 \\
\hline Turnip greens, cooked & I/2 cup (72 g) & 20 \\
\hline
\end{tabular}

Note: *Edible portion. with $\beta$-carotene along with vitamins $\mathrm{C}$ and $\mathrm{E}$, zinc, and copper reduced the risk of developing advanced AMD. ${ }^{4}$ The amount of $\beta$-carotene in this intervention was $17 \mathrm{mg}$ (28,640 IU vitamin A) (Table 1), a level that is above the 99th percentile of dietary intakes for both men and women 50 years and older (Table 2). There is no RDA for $\beta$-carotene. Data from various populations suggest that $3-6 \mathrm{mg}$ /day of $\beta$-carotene from food sources is prudent to maintain plasma $\beta$-carotene concentrations in the range associated with a lower risk of various chronic diseases..$^{10}$ The average intake of $\beta$-carotene from foods in the US for men and women over 50 years of age is 2.6 and $2.7 \mathrm{mg} /$ day, respectively (Table 2 ). $\beta$-Carotene-rich foods and some suggested serving sizes are shown in Table 5.

Table 4 Vitamin E content of foods ${ }^{43, *}$

\begin{tabular}{|c|c|c|}
\hline Food & Serving & $\begin{array}{l}\text { Milligrams ( } \alpha \text {-tocopherol } \\
\text { equivalents) }\end{array}$ \\
\hline Almonds, slivered & I/4 cup (27 g) & 7 \\
\hline Corn oil & I tb (14 g) & 2 \\
\hline Peanuts & I/4 cup (37 g) & 3 \\
\hline Peanut butter, smooth & 2 tb (32 g) & 3 \\
\hline Sunflower seeds & I/4 cup (35 g) & 12 \\
\hline Safflower oil & I tb (14 g) & 5 \\
\hline Soybean oil & I tb (I4 g) & I \\
\hline Wheat-germ oil & I tb (14 g) & 20 \\
\hline
\end{tabular}

Note: *Edible portion.

Abbreviation: tb, tablespoon. 
Table $5 \beta$-Carotene content of foods ${ }^{44, *}$

\begin{tabular}{lll}
\hline Food & Serving & Milligrams \\
\hline Apricots, raw & I medium $(35 \mathrm{~g})$ & 0.9 \\
Broccoli, cooked & I/2 cup $(78 \mathrm{~g})$ & 0.8 \\
Cantaloupe, raw & I/2 cup $(78 \mathrm{~g})$ & 1.2 \\
Carrots, raw & I medium $(6 \mathrm{I} \mathrm{g})$ & 5.3 \\
Carrots, cooked & I/2 cup $(78 \mathrm{~g})$ & 6.3 \\
Kale, cooked & I/2 cup $(65 \mathrm{~g})$ & 3.7 \\
Lettuce, romaine & I/2 cup $(38 \mathrm{~g})$ & 0.5 \\
Pepper, red, sweet & I medium $(119 \mathrm{~g})$ & 2.9 \\
Pumpkin, cooked & I/2 cup $(123 \mathrm{~g})$ & 8.5 \\
Spinach, cooked & I/2 cup $(95 \mathrm{~g})$ & 5.0 \\
Spinach, raw & I cup $(38 \mathrm{~g})$ & 2.1 \\
Sweet potato, cooked & I/2 cup $(164 \mathrm{~g})$ & 15.5 \\
Winter squash, cooked & I/2 cup $(85 \mathrm{~g})$ & 3.9 \\
\hline
\end{tabular}

Note: *Edible portion.

While very high intake of dietary $\beta$-carotene is considered to have no adverse affects on health, there should be caution when supplementing with levels well beyond what can be achieved from dietary sources for those at risk for lung cancer. The effect of $\beta$-carotene supplementation on the risk of developing lung cancer was examined in two large randomized, placebo-controlled trials. The Alpha-Tocopherol BetaCarotene (ATBC) cancer-prevention trial evaluated the effects of $20 \mathrm{mg} /$ day of $\beta$-carotene and/or $50 \mathrm{mg} /$ day of $\alpha$-tocopherol on male heavy smokers. ${ }^{18}$ The Beta-Carotene and Retinol Efficacy Trial (CARET) evaluated the effects of a combination of $30 \mathrm{mg} /$ day of $\beta$-carotene and 25,000 IU/day of retinol (vitamin A) in men and women who were smokers, former smokers, or had a history of occupational asbestos exposure. ${ }^{19}$ Unexpectedly, the risk of lung cancer in the groups taking $\beta$-carotene supplements was increased by $16 \%$ after 6 years in ATBC and increased by $28 \%$ after 4 years in CARET. The reasons for the increase in lung cancer risk are thought to be due to the pro-oxidant effects of high doses of $\beta$-carotene in an oxidative stressed environment, such as a smoker's lung. ${ }^{20}$

\section{Zinc}

Zinc is important in maintaining the health of the retina, given that zinc is an essential constituent of many enzymes ${ }^{5}$ and needed for optimal metabolism of the eye. Zinc ions are present in the enzyme superoxide dismutase, which plays an important role in scavenging superoxide radicals. As related to the eye, zinc plays important roles in antioxidant and immune function. Zinc also plays an important role in the structure of proteins and cell membranes. The structure and function of cell membranes are also affected by zinc. Loss of zinc from biological membranes increases their susceptibility to oxidative damage and impairs their function. ${ }^{21}$ Zinc also plays a role in cell signaling and has been found to influence nerve-impulse transmission.

The RDA for zinc is $11 \mathrm{mg} /$ day for men and $8 \mathrm{mg} /$ day for women ( $\geq 19 \mathrm{yrs}){ }^{5}$ The average intake of zinc from foods in the US for men and women over 50 years of age is meeting this requirement, with averages of 13.5 and $9.8 \mathrm{mg}$ /day, respectively (Table 2). However, men and women in the 25 th percentile of zinc intake have intakes of dietary zinc that do not meet the RDA. Zinc absorption is lower in individuals consuming vegetarian diets; it is recommended that the zinc requirement for this group be twice as much as for nonvegetarians. ${ }^{5}$ Foods rich in zinc and some suggested serving sizes are shown in Table 6.

\section{Lutein and zeaxanthin}

Lutein and zeaxanthin are carotenoids found in high quantities in green leafy vegetables. Unlike $\beta$-carotene, these two carotenoids do not have vitamin A activity. ${ }^{22}$ Of the 20-30 carotenoids found in human blood and tissues, ${ }^{23}$ only lutein and zeaxanthin are found in the lens and retina. ${ }^{24,25}$ Lutein and zeaxanthin are concentrated in the macula or central region of the retina, and are referred to as macular pigment. In addition to their role as antioxidants, lutein and zeaxanthin are believed to limit retinal oxidative damage by absorbing incoming blue light and/or quenching reactive oxygen species. ${ }^{26}$ While there is no RDA for lutein and zeaxanthin, intakes of approximately $6 \mathrm{mg} /$ day have been associated with a decreased risk of AMD. ${ }^{27}$ The current intakes of lutein and zeaxanthin among adults $>50$ years of age falls well below this level, with average intake of $<2 \mathrm{mg}$ /day for both men and women (Table 2). Only men in the 99th percentile of

Table 6 Zinc content of foods ${ }^{43}$

\begin{tabular}{lll}
\hline Food & Serving & Milligrams \\
\hline Almonds, dry roasted & I ounce $(28 \mathrm{~g})$ & 0.9 \\
Beans, baked & I/2 cup (127 g) & 0.9 \\
Beef, cooked & 3 ounces $(85 \mathrm{~g})$ & 1.0 \\
Cashews & I ounce $(28 \mathrm{~g})$ & 1.6 \\
Cereal, cooked, multigrain & I cup (100 g) & 0.6 \\
Cheese, cheddar & I ounce $(28 \mathrm{~g})$ & 0.9 \\
Chicken (dark meat, cooked) & 3 ounces $(85 \mathrm{~g})$ & 1.8 \\
Chickpeas (garbanzo beans) & I/2 cup $(82 \mathrm{~g})$ & 1.3 \\
Corn flakes & I cup $(28 \mathrm{~g})$ & 0.3 \\
Crab, dungeness, cooked & 3 ounces $(85 \mathrm{~g})$ & 4.7 \\
Milk & I cup $(244 \mathrm{~g})$ & 1.2 \\
Oysters, cooked & 3 medium $(75 \mathrm{~g})$ & 24.9 \\
Peanuts & I ounce $(28 \mathrm{~g})$ & 0.9 \\
Pork, cooked & 3 ounces $(85 \mathrm{~g})$ & 2.2 \\
Turkey (dark meat, cooked) & 3 ounces $(85 \mathrm{~g})$ & 3.8 \\
Yogurt, fruit & I cup (227 g) & 1.8 \\
\hline
\end{tabular}


lutein/zeaxanthin intake and women in the 95th percentile meet the dietary intakes that have been related to decreased risk of AMD. In general, lutein and zeaxanthin are found in many of the same foods, and most dietary databases include them together. Because there has been discussion on their individual roles in eye health, Perry et al have analyzed lutein and zeaxanthin separately in food. ${ }^{28}$ Lutein- and zeaxanthin-rich foods and some suggested serving sizes are shown in Table 7.

\section{Omega-3 fatty acids}

In addition to the antioxidants cited above, the omega-3 fatty acids DHA and EPA are thought to be important in AMD prevention. The omega-3 fatty acids have a number of actions that provide neuroprotective effects in the retina. This includes modulation of metabolic processes affecting oxidative stress, inflammation, and vascularization. ${ }^{2}$ DHA is a key fatty acid found in the retina, and is present in large amounts in this tissue. ${ }^{29}$ Tissue DHA status affects retinal cell-signaling mechanisms involved in phototransduction. ${ }^{2}$ It has been suggested that atherosclerosis of the blood vessels that supply the retina contributes to the risk of AMD, similar to the mechanism involved in coronary heart disease,$^{30}$ suggesting that the same dietary fats related to coronary heart disease may also be related to AMD. ${ }^{31,32}$ In addition, long-chain omega-3 fatty acids may have another role in the function of the retina. Biophysical and biochemical properties of DHA may affect photoreceptor-membrane function by altering permeability, fluidity, thickness, lipidproteins. $^{2}$

There is no RDA for EPA/DHA. As stated above, the protective effects of omega-3 fatty acids in ocular health are thought to be similar to those for heart health. The dietary recommendations set up by the American Heart Association for EPA/DHA are largely based on cardiovascular health. Individuals with no history of coronary heart disease or

Table 7 Lutein/zeaxanthin content of foods ${ }^{44, *}$

\begin{tabular}{lll}
\hline Food & Serving & Milligrams \\
\hline Broccoli, cooked & I/2 cup (78 g) & I.7 \\
Brussels sprouts, cooked & I/2 cup (78 g) & $\mathrm{I} .0$ \\
Corn, sweet, cooked & $\mathrm{I} / 2$ cup $(75 \mathrm{~g})$ & $\mathrm{I} .4$ \\
Kale, cooked & $\mathrm{I} / 2$ cup $(65 \mathrm{~g})$ & $\mathrm{I} 0.3$ \\
Lettuce, raw, romaine & $\mathrm{I} / 2$ cup $(38 \mathrm{~g})$ & $\mathrm{I} . \mathrm{I}$ \\
Peas, green, cooked & $\mathrm{I} / 2$ cup $(80 \mathrm{~g})$ & $\mathrm{I} . \mathrm{I}$ \\
Spinach, cooked & $\mathrm{I} / 2$ cup $(95 \mathrm{~g})$ & 6.7 \\
Spinach, raw & $\mathrm{I} / 2$ cup $(38 \mathrm{~g})$ & 4.5 \\
\hline
\end{tabular}

Note: *Edible portion. phase properties, and the activation of membrane-bound

myocardial infarction are recommended to consume oily fish or fish oils two times per week. ${ }^{33}$ Those having been diagnosed with coronary heart disease after infarction should consume $1 \mathrm{~g}$ EPA + DHA per day from oily fish or supplements. The FDA has advised that adults can safely consume a total of $3 \mathrm{~g}$ per day of combined DHA and EPA, with no more than $2 \mathrm{~g}$ per day coming from dietary supplements. ${ }^{33}$

The current intakes for EPA/DHA among men and women $>50$ years of age are 121 and $13 \mathrm{mg} /$ day, respectively (Table 2). EPA/DHA-rich foods and some suggested serving sizes are shown in Table 8.

\section{Recommendations}

To date, the evaluation of a single nutrient in the prevention of age-related eye diseases has not been entirely consistent. The inconsistencies among studies in terms of which nutrients and the amount of nutrients required for protection make it difficult to make specific recommendations for dietary intakes. It is likely that nutrients are acting synergistically to provide protection. Therefore, it may be more practical to recommend food choices rich in vitamins $\mathrm{C}$ and $\mathrm{E}$, $\beta$-carotene, zinc, lutein and zeaxanthin, and omega-3 fatty acids. Such a recommendation may also provide benefit from possible other components in food that may be important. Therefore, an awareness of dietary sources of key nutrients

Table 8 EPA + DHA content in fish ${ }^{33}$

\begin{tabular}{ll}
\hline Fish & $\begin{array}{l}\text { EPA + DHA, g/3 oz (85 g) } \\
\text { serving (edible portion) }\end{array}$ \\
\hline Trout & \\
$\quad$ Farmed & 0.15 \\
Wild & 0.20 \\
Crab, Alaskan king & 0.35 \\
Flounder/sole & 0.42 \\
Haddock & 0.20 \\
Halibut & $0.40-1.00$ \\
Herring & \\
Atlantic & 1.71 \\
Pacific & 1.81 \\
$\quad$ Mackerel & $0.34-1.57$ \\
Salmon & \\
Atlantic, farmed & $1.09-1.83$ \\
Atlantic, wild & $0.90-1.56$ \\
Chinook & 1.48 \\
Sockeye & 0.68 \\
Sardines & $0.98-1.70$ \\
Shrimp, mixed species & 0.27 \\
Tuna & \\
Fresh & $0.24-1.28$ \\
White, canned in water, drained & 0.73 \\
\hline Abbreviations: EPA, eicosapentaenoic acid; DHA, docosahexaenoic acid.
\end{tabular}


important for ocular health is important for both the patient and health-care provider. Good sources of vitamin $\mathrm{C}$ include citrus fruit, berries, tomatoes, and broccoli (Table 3). Good sources of vitamin $\mathrm{E}$ are vegetable oils, wheat germ, nuts, and legumes (Table 4). $\beta$-Carotene can be found in carrots, apricots, sweet potatoes, and pumpkins (Table 5). Oysters, beef, and other meats are rich sources of zinc. Nuts, legumes, and dairy are relatively good plant sources of zinc (Table 6). The two foods that were found to have the highest amounts of lutein and zeaxanthin were kale and spinach (Table 7). Other major sources include broccoli, peas, and brussels sprouts. Fish oils are the primary source of omega-3 fatty acids (Table 8 ).

A healthy diet including a variety of fresh fruit and vegetables, legumes, lean meats, dairy, fish, and nuts, will have many benefits and will be a good source of the antioxidant vitamins and minerals implicated in the etiology of age-related eye health. There is no evidence that nutrient-dense diets high in these foods, which provide known and unknown antioxidant components, are harmful. In fact, intake of fruits, vegetables, and legumes is associated with reduced risk of death due to cancer, cardiovascular disease, and all causes. ${ }^{34-36}$ Such a dietary recommendation does not appear to be harmful and may have other benefits, despite its unproven efficacy in preventing or slowing age-related eye disease. Furthermore, the hypothesis that antioxidant and anti-inflammatory nutrients may be of benefit in age-related eye health is plausible, given the role of oxidative damage and inflammation in the etiology of age-related eye diseases.

The AREDS1 trial found that supplementation with vitamins $\mathrm{C}$ and $\mathrm{E}, \beta$-carotene, zinc, and copper reduces the risk of developing advanced AMD. Based on the supporting literature, including observations from AREDS1, AREDS2 will evaluate lutein, zeaxanthin, and the omega-3 fatty acids EPA and DHA on reducing the risk of advanced AMD. Although AREDS1 supports a role for these nutrients in $\mathrm{AMD}$, it is reasonable to believe that they are also important for the prevention or treatment of other major age-related eye diseases, given the role of oxidative stress and inflammation in their etiologies. ${ }^{37}$ In fact, the American Academy of Ophthalmology has developed guidelines for the use of omega-3 fatty acids for potential benefit in dry eye. ${ }^{38}$ Dietary data from NHANES indicate that the intake of the key ocular nutrients may be inadequate in those $\geq 50$ years of age. This gap may be filled by creating an awareness of these nutrients and their dietary sources. Therefore, an educational tool may be useful to aid in the selection of food/nutrient choices for optimal eye health.

\section{Efforts at nutrition and eye-health education}

As previously discussed, there have been a number of important studies affirming the relationship of diet to the treatment, prevention, and/or slowing progression of a variety of age-related ocular illnesses. Educational campaigns have been initiated by the federal government and public health associations as well as the eye-vision industry to heighten the awareness of a link between nutrition and eye-health link. ${ }^{39-42}$ To this end, an educational vision icon (M'eyeDiet, Figure 1) was developed to promote awareness of the importance of a healthy diet, targeting the aforementioned eye-health nutrients.

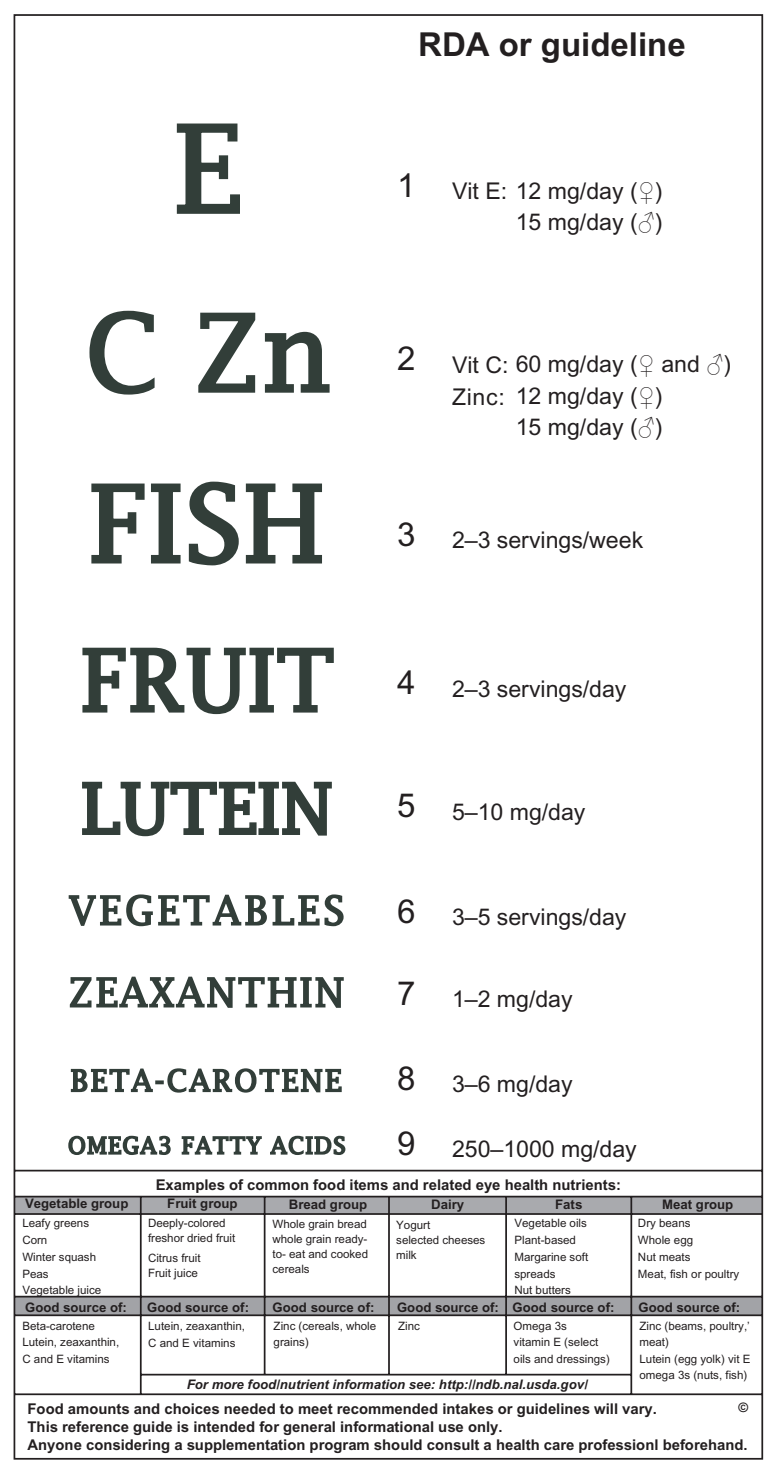

Figure I M'eyeDiet: an educational tool on nutrition and eye health. 
This graphic presents a suggested recommended daily intake for each nutrient. This poster can be placed in medical clinics, senior centers/assisted living areas, optometrist and ophthalmologist offices, wellness centers and food supermarkets, as well as being posted in a personal health-reminder area of one's home. Since nutrients are more conceptual, and hence are invisible to consumers, "good vision food" items and the correct food serving size information should be available to the client/patient/consumer to make the necessary translation from nutrients to food.

A simple food guide to help individuals choose rich food sources as a tear-off page attached to the graphic itself or as a stand-alone pamphlet can be included to encourage the discussion and practice of selecting the best food choices for healthy vision. The guide shown here is formed based on food groupings (vegetables, fruits, breads, dairy, fats, meats [meat and nonmeat high-protein sources]). Anyone considering a supplementation program to meet recommended intakes should consult a health-care professional beforehand.

\section{Acknowledgments}

The authors would like to thank Huifen Wang, $\mathrm{PhD}$ for his assistance on NHANES data retrieval and Emily S Mohn, BS for her assistance with the organization of the NHANES data. This study was supported by USDA 58-1950-7-707, Bausch and Lomb and the contribution to the research of H.M.R. of an anonymous donor. Any opinions, findings, conclusions, or recommendations expressed in this publication are those of the author and do not necessarily reflect the view of the US Department of Agriculture.

\section{Disclosure}

The authors report no conflicts of interest in this work.

\section{References}

1. Chiu CJ, Taylor A. Nutritional antioxidants and age-related cataract and maculopathy. Exp Eye Res. 2007;84:229-245.

2. SanGiovanni JP, Chew EY. The role of omega-3 long-chain polyunsaturated fatty acids in health and disease of the retina. Prog Retin Eye Res. 2005;24:87-138.

3. Ocular Nutrition Society. Baby boomers value vision more than any other sense but lack focus on eye health. 2011. Available from: http://www. ocularnutritionsociety.org/boomers. Accessed September 21, 2012.

4. Age-Related Eye Disease Study Research Group. A randomized, placebocontrolled, clinical trial of high-dose supplementation with vitamins C and $\mathrm{E}$, beta carotene, and zinc for age-related macular degeneration and vision loss: AREDS report no 8. Arch Ophthalmol. 2001;119:1417-1436. Erratum in Arch Ophthalmol. 2008;126:1251.

5. Panel on Micronutrients, Subcommittees on Upper Reference Levels of Nutrients and of Interpretation and Use of Dietary Reference Intakes, Standing Committee on the Scientific Evaluation of Dietary Reference Intakes. Dietary Reference Intakes for Vitamin A, Vitamin K, Arsenic, Boron, Chromium, Copper, Iodine, Iron, Manganese, Molybdenum, Nickel, Silicon, Vanadium, and Zinc. Washington: National Academies Press; 2002.
6. Age-Related Eye Disease Study Research Group, SanGiovanni JP, Chew EY, et al. The relationship of dietary carotenoid and vitamin $\mathrm{A}, \mathrm{E}$ and $\mathrm{C}$ intake with age-related macular degeneration in a case-control study: AREDS report no 22. Arch Ophthalmol. 2007;125: 1225-1232.

7. Sangiovanni JP, Agrón E, Meleth AD, et al. $\omega$-3 Long-chain polyunsaturated fatty acid intake and 12-y incidence of neovascular age-related macular degeneration and central geographic atrophy: AREDS report 30, a prospective cohort study from the Age-Related Eye Disease Study. Am J Clin Nutr. 2009;90:1601-1607.

8. The Age-Related Eye Disease Study 2 (AREDS2) Research Group. Lutein + zeaxanthin and omega-3 fatty acids for age-related macular degeneration. The Age-Related Eye Disease Study 2 (AREDS2) Randomized Clinical Trial. JAMA. 2013;309(19):2005-2015.

9. Gregory JF 3rd. Ascorbic acid bioavailability in foods and supplements. Nutr Rev. 1993;51:301-303.

10. Panel on Dietary Antioxidants and Related Compounds, Subcommittee on Upper Reference Levels of Nutrients, Subcommittee on Interpretation and Uses of DRIs, Standing Committee on the Scientific Evaluation of Dietary Reference Intakes. Dietary Reference Intakes for Vitamin C, Vitamin E, Selenium, and Carotenoids. Washington: National Academies Press; 2000.

11. Taylor A, Jacques PF, Nowell T, et al. Vitamin C in human and guinea pig aqueous, lens and plasma in relation to intake. Curr Eye Res. 1997; 16:857-864.

12. Carr AC, Frei B. Toward a new recommended dietary allowance for vitamin $\mathrm{C}$ based on antioxidant and health effects in humans. Am J Clin Nutr. 1999;69:1086-1107.

13. Centers for Disease Control and Prevention. National Health and Nutrition Examination Survey. Available from: http://www.cdc.gov/nchs/ nhanes.htm. 2013. Accessed May 21, 2013.

14. Traber MG. Utilization of vitamin E. Biofactors. 1999;10:115-120.

15. Traber MG. Vitamin E. In: Shils ME, Shike M, Ross AC, Caballero B, Cousins RJ, editors. Modern Nutrition in Health and Disease. Philadelphia: Lippincott Williams \& Wilkins; 2006:396-411.

16. Traber MG. Does vitamin E decrease heart attack risk? Summary and implications with respect to dietary recommendations. J Nutr. 2001;131:395S-397S.

17. Krinsky NI, Johnson EJ. Carotenoid actions and their relation to health and disease. Mol Aspects Med. 2005;26:459-516.

18. [No authors listed]. The effect of vitamin $\mathrm{E}$ and beta-carotene on the incidence of lung cancer and other cancers in male smokers. The AlphaTocopherol, Beta-Carotene Cancer Prevention Study Group. $N$ Engl J Med. 1994;330:1029-1035.

19. Omenn GS, Goodman GE, Thornquist MD, et al. Effects of a combination of beta-carotene and vitamin A on lung cancer and cardiovascular disease. N Engl J Med. 1996;334:1150-1155.

20. Wang XD, Russell RM. Procarcinogenic and anticarcinogenic effects of beta-carotene. Nutr Rev. 1999;57:263-272.

21. O'Dell BL. Role of zinc in plasma membrane function. J Nutr. 2000; 130:1432S-1436S.

22. Johnson EJ. The role of carotenoids in human health. Nutr Clin Care. 2002;5:56-65.

23. Parker RS. Carotenoids in human blood and tissues. J Nutr. 1989;119: 101-102.

24. Yeum KJ, Shang F, Schalch W, Russell RM, Taylor A. Fat-soluble nutrient concentrations in different layers of human cataractous lens. Curr Eye Res. 1999;19:502-505.

25. Bone RA, Landrum JT, Tarsis SL. Preliminary identification of the human macular pigment. Vision Res. 1985;25:1531-1535.

26. Krinsky NI. Possible biologic mechanisms for a protective role of xanthophylls. J Nutr. 2002;132:540S-542S.

27. Seddon JM, Ajani UA, Sperduto RD, et al. Dietary carotenoids, vitamins $\mathrm{A}, \mathrm{C}$ and $\mathrm{E}$, and advanced age-related macular degeneration. Eye Disease Case-Control Study Group. JAMA. 1994;272:1413-1420.

28. Perry A, Rasmussen H, Johnson EJ. Xanthophyll (lutein, zeaxanthin) content in fruits, vegetables and corn and egg products. J Food Compost Anal. 2009;22:9-15. 
29. Fliesler SJ, Anderson RE. Chemistry and metabolism of lipids in the vertebrate retina. Prog Lipid Res. 1983;22:79-131.

30. Sarks SH, Sarks JP. Age-related macular degeneration: atrophic form. In: Ryan SJ, Schachat SP, Murphy RM, editors. Retina. St Louis (MO): Mosby; 1994:149-173.

31. Cho E, Hung S, Seddon JM. Nutrition and age-related macular degeneration: a review. In: Berger JW, Fine SL, Maquire MG, editors. Age-Related Macular Degeneration. St Louis (MO): Mosby; 1998:57-67.

32. Snow KK, Seddon JM. Do age-related macular degeneration and cardiovascular disease share common antecedents? Ophthal Epidemiol. 1999;6:125-143.

33. Kris-Etherton PM, Harris WS, Appel LJ. Fish consumption, fish oil, omega-3 fatty acids, and cardiovascular disease. Circulation. 2002;106:2747-2757.

34. Wiseman M. The second World Cancer Research Fund/American Institute for Cancer Research expert report. Food, nutrition, physical activity, and the prevention of cancer: a global perspective. Proc Nutr Soc. 2008;67:253-256.

35. Nöthlings $U$, Schulze MB, Weikert C, et al. Intake of vegetables, legumes, and fruit, and risk for all-cause, cardiovascular, and cancer mortality in a European diabetic population. $J$ Nutr. 2008;138:775-781.

36. Law MR, Morris JK. By how much does fruit and vegetable consumption reduce the risk of ischaemic heart disease? Eur J Clin Nutr. 1998;52:549-556.

37. Vishwanathan R, Johnson EJ. Eye disease. In: Erdman JW, MacDonald IA, Zeisel SH, editors. Present Knowledge in Nutrition. 10th ed. Ames (IA): Wiley-Blackwell; 2012.
38. American Academy of Ophthalmology. Preferred Practice Pattern guidelines. Dry-eye syndrome: limited revision. Available from: http:// one.aao.org/CE/PracticeGuidelines/PPP_Content.aspx?cid=127dbdce4271-471a-b6d9-464b9d15b748. Accessed January 22, 2013.

39. Centers for Disease Control and Prevention. Vision Health Initiative (VHI) [website]. Available from: http://www.cdc.gov/visionhealth. Accessed November 24, 2012.

40. National Eye Institute. National Eye Health Education Program: Vision and aging. Available from: http://www.nei.nih.gov/nehep/programs/ visionandaging/index.asp. Accessed November 24, 2012.

41. Bausch and Lomb. The Joy of Sight [website]. Available from: http:// www.alcon.com/eye-health/vision-problems.aspx. Accessed November 24, 2012.

42. Alcon. The world of eye health. Available from: http://www.alcon.com/ eye-health/vision-problems.aspx. Accessed May 21, 2013.

43. US Department of Agriculture, Agricultural Research Service. USDA National Nutrient Database for Standard Reference. 2010. Available from: http://www.ars.usda.gov/Services/docs.htm? docid=8964. Accessed May 21, 2013.

44. US Department of Agriculture. USDA-NCC Carotenoid Database for US Foods - 1998. Available from: https://www.ars.usda.gov/SP2UserFiles/Place/12354500/Data/SR25/nutrlist/sr25a338.pdf. Accessed November 1, 2012.
Clinical Interventions in Aging

\section{Publish your work in this journal}

Clinical Interventions in Aging is an international, peer-reviewed journal focusing on evidence-based reports on the value or lack thereof of treatments intended to prevent or delay the onset of maladaptive correlates of aging in human beings. This journal is indexed on PubMed Central, MedLine, the American Chemical Society's 'Chemical Abstracts

\section{Dovepress}

Service' (CAS), Scopus and the Elsevier Bibliographic databases. The manuscript management system is completely online and includes a very quick and fair peer-review system, which is all easy to use. Visit http://www.dovepress.com/testimonials.php to read real quotes from published authors. 